mối tương quan với tiền sử bệnh lý kèm theo, phân loaii phẫu thuật, cách thức phẫu thuật, thời gian phẫu thuật, tình trạng đặt dẫn lưu sau mổ, ngoài ra chỉ sổ nguy cơ NKVM còn có mối tương quan tuổi, phân loại ASA, hình thức phẫu thuật.

Thời gian nằm điều trị sau mổ của nhóm bệnh nhân có nhiễm trùng vết mổ $(20,82 \pm 5,82$ ngày) dài hơn nhiều so với nhóm bệnh nhân không có nhiễm trùng vết mổ $(8,81 \pm 4,35$ ngày).

\section{TÀI LIỆU THAM KHẢO}

1. Bộ Y tế (2016), Quyết định số 1886/QĐ-BYT phê duyệ̂t "Kể hoạch hành động quốc gia vể kiểm soát nhiếm khuẩn trong các cơ sở khám bệnh, chữa bệnh giai đoạn 2016 - 2020".

2. Bộ Y tế (2012), "Hướng dẫn phòng ngừa nhiễm khuẩn vết mổ", Ban hành kèm theo Quyết định số: 3671/Qð -BYT ngày 27 tháng 9 năăm 2012 của Bộ Y tế.

3. Nguyến Quốc Anh, Nguyến Viêtt Hùng và Phạm Ngọc Trường (2012), "Tỷ lệ mới mắc và yếu tố nguy cơ nhiễm khuẩn vết mổ tại một số bệnh viện của Việt Nam, 2009 - 2010", Tạp chí Y học thực hành, $\mathbf{8 3 0 ( 7 )}$, tr. 28-32.

4. Meyer E., Schwab F., Gastmeier P. và các cộng sự." (2006), "Surveillance of antimicrobial use and antimicrobial resistance in German intensive care units (SARI): a summary of the data from 2001 through 2004", Infection, 34(6), tr. 303-9.

5. World Health Organization (2009), Prevention of hospital acquired, A practical guide 2 nd edition, Geneva, Switzerland.

6. Lê Minh Luân (2006), "Nghiên cứu sử dụng kháng sinh dự phông và một sỗ yếu tố nguy cớ nhiễm khuẩn vết mổ trong phẫu thuật tiểu hóa bệnh viện Việt Đức Hà Nội", Đề tài thạc sĩ, Trường đại họ Y Y Hà Nội.

7. Nguyễn Viêt Hùng và Nguyễn Quốc Anh (2010), "Nhận xét vể tỷ lệ mắc, yếu tố nguy cớ, tác nhân gây bệnh và hậu quả của nhiễm khuẩn vết mổ tại một số bệnh viện tỉnh khu vực miền Bắc (2009 - 2010)", Y học lẩm sàng, sổ 52 (tháng $5 / 2010)$, tr. 16 - 23.

\title{
THỰC TRẠNG KIẾN THỨC, THÁI Độ VỀ COVID-19 CỦA SINH VIÊN ĐIỀU DƯ ỚNG TRƯỜ'NG CAO ĐẲNG Y TẾ HÀ NỘI NĂM 2020
}

\author{
Trần Thị Nguyệt ${ }^{1}$, Trần Quỳnh Anh ${ }^{2}$, Nguyễn Thị Nguyệt ${ }^{4}$, \\ Bùi Văn Tùng ${ }^{2}$, Nguyễn Thị Hoa Huyền ${ }^{3}$
}

\section{TÓM TẮT}

Mục tiêu: Mô tả kiến thức, thái độ của sinh viên Điều dưỡng trường Cao đằng Y tế Hà Nội về Covid-19 năm 2020. Đối tượng và phương pháp nghiên cứu: Nghiên cứu mô tả cắt ngang được thực hiện trên 597 sinh viên điêu dưỡng trường Cao đẳng $Y$ tế Hà Nội. Kết quả: Điểm trung bình cho kiến thức, thái độ là $9,3 \pm 1,7$ và $44,8 \pm 7,2$. Phần lớn sinh viên có kiến thức đúng về tác nhân gây bệnh $(85,4 \%)$, đường truyền bệnh $(99,0 \%)$, thời gian ủ bệnh $(89,1 \%)$ và mang phương tiện phòng hộ cá nhân $(89,0 \%)$. Về thái độ của sinh viên, hâu hết sinh viên đều có thái độ tích cực về COVID-19, bên cạnh đó có môtt tỷ lệ đáng kể có thái độ tiêu cực về nguy cơ lây nhiếm cho bản thân $(30,4 \%)$ và gia đình $(28,2 \%)$. Điểm kiến thức và thái độ có sự khác biệt giữa giới tính, nguồn thông tin về COVID-19 được cung cấp từ Bộ Y tế/trường đại họccao đẳng/ người thân/bạn bè $(p<0,05)$. Kết luận: Nói chung, tỷ lệ sinh viên điều dưỡng có kiến thức tốt về COVID-19 khá cao; trong đó, tỷ lệ có kiến thức chưa

\footnotetext{
${ }^{1}$ Trường Cao đẳng Y tế Hà Nội;

2Viện đào tạo Y họ dự phòng và Y tế công cộng, Trường Đai học Y Hà Nối

${ }^{3}$ Viện Khoa học Sức khỏe, Trường Đại học VinUni;

${ }^{4}$ Đai hoc Y Dướ-Đai hoc Quốc Gia Hà Nôi.

Chịu trách nhiệm chính: Trân Thị Nguyệt

Email: tranthinguyet1402@gmail.com

Ngày nhận bài: 8.7.2021

Ngày phản biên khoa học: 3.9.2021

Ngày duyệt băi: 13.9.2021
}

đúng còn gặp nhiều ở các câu hỏi liên quan đến điều trị, các triệu chứng về COVID-19 và hệ thống dự phòng bệnh tại Việt Nam, đa phần sinh viên đã có thái độ tích cực về COViD-19. Các khía cạnh kiến thức nêu trền, giới tính và nguồn thông tin về COVID-19 cần được xem xét khi thực hiện các khóa đào tạo về sức khỏe cộng đồng cho sinh viên.

Tư khóa: COVID-19, kiến thức, thái độ, sinh viên Điều dưỡng

\section{SUMMARY}

\section{LEVELS OF KNOWLEDGE AND ATTITUDE ABOUT COVID-19 OF NURSING STUDENTS AT HANOI MEDICAL COLLEGES, 2020}

Objective: To describe levels of knowledge and attitudes of nursing students at Hanoi Medical College about Covid-19. Methods and subjects: A crosssectional descriptive study was conducted on 597 nursing students at Hanoi Medical College. Results: The average score for knowledge and attitude were $9.3 \pm 1.7$ and $44.8 \pm 7.2$, respectively. Majority of the study's participants had correct knowledge about pathogens $(85.4 \%)$, transmission route $(99.0 \%)$, incubation period ( $89.1 \%)$ and wearing personal protective equipment (89.0\%). Regarding students' attitudes, most students had a positive attitude about COVID-19, besides a significant proportion of the participants had a negative attitude about the risk of self-infection $(30.4 \%)$ and family $(28.2 \%)$. There were significant differences in knowledge and attitude scores between genders, sources of information about COVID-19 from the Ministry of Health/universities and 
colleges/relatives/friends $(p<0.05)$. Conclusion: In general, the percentage of nursing students with good knowledge about COVID-19 is quite high; In which, the rate of having incorrect knowledge is still high in questions related to treatment, symptoms of COVID-19 and the disease prevention system in Vietnam, most of the students had a positive attitude. about COVID-19. The above knowledge aspects, gender and sources of information about COVID-19 should be considered when conducting public health training courses for students.

Keywords: COVID-19, knowledge, attitude, nursing students

\section{I. Đă̆T VẤN ĐỀ}

Vào tháng 12 năm 2019, bệnh do Coronavirus (COVID-19) lần đâu tiên được báo cáo tại thành phố Vũ Hán, tỉnh Hồ Bắc, Trung Quốc [1], và nhanh chóng lây lan trên toàn câu gây nên một cuộc khủng hoảng y tế nghiêm trọng ở nhiều quốc gia và khu vực trên thế giới[2]. Tại Viêt Nam trường hợp COVID-19 đâu tiên được công bố vào ngày 23 tháng 1 năm 2020, trải qua 4 đợt dịch, tính đến ngày 24/6/2021 hơn 14.000 trường hợp nhiễm đã được ghi nhận với 72 trường hợp tử vong đã được báo cáo[3]. Bộ Y tế đã thông báo huy động toàn bộ lực lượng y tế tham phòng chống và kiểm soát đại dịch COVID-19, trong đó có sinh viên tại các trường đại học, cao đằng trong khối ngành chăm sóc sức khỏe bao gôm sinh viên y khoa và sinh viên điêuu dưỡng.

Vai trò của sinh viên điều dưỡng trong việc tham gia phòng chống dich bênh là rất cân thiết, đây là lực lượng trẻ, năng động và nhiệt huyết; tuy nhiên, vẫn cân phải được trang bị kiến thức, thái độ đây đủ về bênh COVID-19 và các biện pháp phòng chống trước và trong khi tham gia các hoạt động chống dịch. Nghiên cứu của Azal Ikhlaq và cộng sự (2020) chỉ ra rằng $80 \%$ sinh viên có đủ kiến thức về COVID-19, trên $80 \%$ sinh viên có thái độ tích cực[5]. Một nghiên cứu khác tại Thiểm Tây Trung Quốc chỉ ra 82,3\% sinh viên có kiến thức đúng và $73,8 \%$ sinh viên có thái độ tích cực về Covid-19 [6].

Mặc dù có nhiều những nghiên cứu liên quan đến COVID-19 đã được công bố, tuy nhiên tại Việt Nam có rất ít những dữ liệu về mức độ kiến thức, thái độ của sinh viên điêu dưỡng về COVID19. Bên cạnh đó nhằm hỗ trợ xây dựng một chương trình đào tạo nhằm trang bi một cách phù hợp các nội dung kiến thức, thái độ về COVID-19 cho sinh viên chúng tôi thực hiện nghiên cứu với mục tiêu: Mô tả kiến thức, thái độ của sinh viên Điều dương trường Cao đằng Y tế Hà Nội về Covid 19 năm 2020.

\section{II. ĐỐI TƯỢNG VÀ PHƯƠNG PHÁP NGHIÊN CỨU \\ 1. Đối tượng nghiên cứu: Sinh viên Cao}

đẳng điều dưỡng hệ chính quy từ năm thứ nhất đến năm thứ 3 trường Cao đẳng $Y$ tế Hà Nội

2. Thời gian và địa điểm nghiên cứu: từ tháng 10 đến 11/2020, Trường Cao đẳng Y Tế Hà Nội

3. Phương pháp nghiên cứu

Thiết kế nghiên cứu: mô tả cắt ngang

Cỡ mẫu: Áp dụng công thức tính cỡ mẫu cho một tỷ lệ

$$
n=Z_{(1-a / 2)} \frac{p(1-p)}{(p \varepsilon)^{2}}
$$

n: là cõ mẫu tối thiểu; $Z_{(1-a / 2)}$ : Là hệ số tin cậy (với độ tin cậy 95\%, z=1,96).

a : Mức ý nghĩa thống kê (sử dụng $a=0,05$ ).

p: Tỷ lệ sinh viên Y khoa có kiến thức đúng vê COVID-19 theo nghiên cứu của Azal Ikhlaq (2020) với $p=0,8[5]$

$\varepsilon$ : Độ chính xác tương đối (sử dụng $\varepsilon^{\varepsilon}=0,05$ )

Từ công thức trên tính được cỡ mẫu $n=384$. Lây thêm 15\% đối tượng để đảm bảo cõ mẫu tối thiểu, cõ mẫu cân thu thập là 442. Trên thực tế chúng tôi thu thập được 597 sinh viên.

Phương pháp chọn mẫu: Áp dụng phương pháp chọn mẫu phân tâng theo thứ tự năm học của sinh viên. Số lượng sinh viên lấy vào mẫu là: Năm thứ ba 197 sinh viên, năm thứ hai 202 sinh viên và năm thứ nhất 198 sinh viên

\section{Công cụ và tiêu chuẩn đánh giá}

Thang đo kiến thức của sinh viên: Bao gồm 13 câu hỏi, mỗi câu hỏi trả lời đúng được 1 điểm, sai không được điểm. Tổng điểm kiến thức của sinh viên dao động từ 0 đến 13 điểm bao gôm 8 câu hỏi đánh giá theo thang Likert 7 chia làm 3 nhóm thái độ tiêu cực, thái độ trung lập và thái độ tích cực. Điểm thái độ là tổng số điểm cho cả 8 câu hỏi, dao động từ 8 đến 56 điểm Thang đo thái độ của sinh viên: bao gồm 8 câu hỏi đánh giá theo thang Likert 7 chia làm 3 nhóm thái độ tiêu cực, thái độ trung lập và thái độ tích cực. Điểm thái độ là tổng số điểm cho cả 8 câu hỏi, dao động từ 8 đến 56 điểm

5. Phương pháp thu thập số liệu: Số liệu được thu thập bằng bộ câu hỏi tự điền

6. Phương pháp phân tích số liệu: Số liệu sau khi được làm sạch, được phân tích bằng phần mềm kê SPSS 22.0.

\section{KẾT QUẢ NGHIÊN CỨU}

Thông tin chung của đối tượng nghiên cứu: Nghiên cứu của chúng thôi thực hiện trên 597 đối tượng nghiên cứu là sinh viên điều dưỡng trường Cao đằng $Y$ Hà Nội. Trong đó phân lớn đối tượng là nữ giới chiếm 79,1\%.Có 39,5\% sinh viên báo cáo gia đình mình có người làm trong ngành y tế. Đa phân sinh viên sống ở 
thành thị $(62,3 \%)$ và sống cùng với bố mẹ/người viên tiếp thu được, đến chủ yếu từ Bộ $Y$ tế thân (50,8\%). Nguồn kiến thức về COVID-19 sinh $\quad(58,0 \%)$ và cộng đồng $(56,0 \%)$.

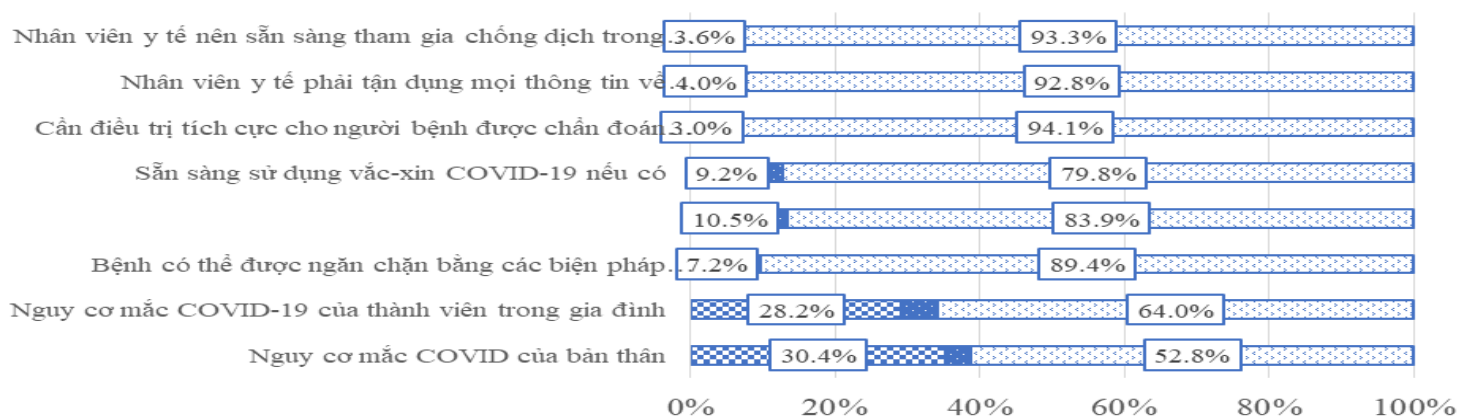

国 Thái độ tiêu cực $:$ Thái độ trung lập 四Thái độ tích cực

Biểu đồ 1. Thái độ của sinh viên điều dướng về COVID-19

Nhận xét: Hầu như sinh viên đều có thái độ tích cực COVID-19 trong các nội dung như: sẵn sàng tham gia chống dịch trong cộng đồng $(93,3 \%)$; phải tận dụng mọi thông tin về COVID-19 (92,8\%); cần điêu trị tích cực cho người bệnh được chẩn đoán nhiễm COID-19 (94,1\%). Bên cạnh đó cũng có $30,4 \%$ sinh viên có thái độ tiêu cực về nguy cơ mắc COVID-19 của bản thân; $28,2 \%$ có thái độ tiêu cực về nguy cơ mắc COVID-19 của thành viên trong gia đình.

Bảng 1. Kiến thức của sinh viên điều dưỡng về COVID-19

\begin{tabular}{|c|c|c|}
\hline Nội dung kiến thức & Số lượng (n) & Tỷ lệ trả lời đúng(\%) \\
\hline Tác nhân gây bệnh COVID-19 & 510 & 85,4 \\
\hline Đường truyền bệnh chính & 591 & 99,0 \\
\hline Triệu chứng thường gặp của bệnh COVID-19 & 328 & 54,9 \\
\hline Thời gian ủ bệnh trung bình của COVID-19 & 532 & 89,1 \\
\hline Thuốc điều trị COVID-19 & 190 & 31,8 \\
\hline Thời gian rửa tay để phòng ngừa COVID-19 & 356 & 59,6 \\
\hline Nhóm bệnh nhân có nguy cơ tử vong cao do COVID-19 & 535 & 89,6 \\
\hline Hệ thống cách li phòng chống COVID-19 tại Việt Nam & 183 & 30,7 \\
\hline Xét nghiệm phân tử chẩn đoán COVID-19 & 423 & 70,9 \\
\hline Điều kiện người bệnh được xuất viện & 452 & 75,7 \\
\hline Sự sằn có của Vắc-xin phòng bệnh COVidD-19 & 429 & 71,9 \\
\hline Nghề nghiệp có nguy cớ cao mắc COVID-19 & 423 & 70,9 \\
\hline Mang phương tiện phòng hộ các nhân & 585 & 98,0 \\
\hline
\end{tabular}

Nhận xét: Hầu như sinh viên đều có kiến thức đúng về nội dung: đường lây truyền bệnh chính (99,0\%); mang phương tiện phòng hộ cá nhân $(98,0 \%)$; thời gian ủ bệnh trung bình $(89,1 \%)$; nhóm bệnh nhân có nguy cơ tử vong cao $(89,6 \%)$ và tác nhân gây bệnh $(85,4 \%)$.

Bảng 2. Yếu tố tương quan với kiến thức và thái độ của sinh viên điều dưỡng về COVID-19

\begin{tabular}{|c|c|c|c|c|c|}
\hline \multirow{2}{*}{\multicolumn{2}{|c|}{ (n) }} & \multicolumn{2}{|c|}{ Kiến thức } & \multicolumn{2}{|c|}{ Thái độ } \\
\hline & & Mean \pm SD & $\mathbf{p}$ & Mean \pm SD & $\mathbf{p}$ \\
\hline \multicolumn{2}{|c|}{ Điểm trung bình chung } & $9,3 \pm 1,7$ & - & $44,8 \pm 7,2$ & - \\
\hline \multirow{2}{*}{ Giới tính } & $\mathrm{Nam}$ & $8,7 \pm 2,0$ & \multirow{2}{*}{$<0,001$} & $45,2 \pm 7,5$ & \multirow{2}{*}{$>0,05$} \\
\hline & Nữ & $9,4 \pm 1,6$ & & $44,7 \pm 7,1$ & \\
\hline \multirow{3}{*}{ Thứ tự năm học } & Năm thứ nhất & $9,1 \pm 1,5$ & \multirow{3}{*}{$>0,05$} & $45,6 \pm 6,9$ & \multirow{3}{*}{$>0,05$} \\
\hline & Năm thứ hai & $9,3 \pm 1,7$ & & $44,3 \pm 7,1$ & \\
\hline & Năm thứ ba & $9,4 \pm 1,8$ & & $44,5 \pm 7,4$ & \\
\hline \multirow{2}{*}{$\begin{array}{l}\text { Gia đình có người làm } \\
\text { trong ngành y tế }\end{array}$} & Có & $9,2 \pm 1,6$ & \multirow{2}{*}{$>0,05$} & $45,1 \pm 7,1$ & \multirow{2}{*}{$>0,05$} \\
\hline & Không & $9,3 \pm 1,7$ & & $44,6 \pm 7,2$ & \\
\hline \multirow{2}{*}{ Nơi ở } & Thành thị & $9,2 \pm 1,7$ & \multirow{2}{*}{$>0,05$} & $44,6 \pm 7,5$ & \multirow{2}{*}{$>0,05$} \\
\hline & Nông thôn & $9,3 \pm 1,6$ & & $45,2 \pm 6,5$ & \\
\hline Hiên nay sống cùng với & Bố me/người thân & $9,4 \pm 1,8$ & $>0,05$ & $45,1 \pm 7,1$ & $>0,05$ \\
\hline
\end{tabular}


VIETNAM MEDICAL JOURNAL N01 - OCTOBER - 2021

\begin{tabular}{|c|c|c|c|c|c|}
\hline & Khác & $9,2 \pm 1,5$ & & $44,5 \pm 7,2$ & \\
\hline \multirow{4}{*}{$\begin{array}{c}\text { Nguôn kiến thức về } \\
\text { COVID-19 }\end{array}$} & Bộ y tế & $9,4 \pm 1,6$ & $<\mathbf{0 , 0 1}$ & $45,5 \pm 6,0$ & $<\mathbf{0 , 0 5}$ \\
\cline { 2 - 6 } & Trường đại học & $9,5 \pm 1,8$ & $>0,05$ & $46,7 \pm 6,4$ & $<\mathbf{0 , 0 0 1}$ \\
\cline { 2 - 6 } & Người thân/bạn bè & $9,6 \pm 1,7$ & $<\mathbf{0 , 0 5}$ & $46,2 \pm 6,3$ & $<\mathbf{0 , 0 5}$ \\
\cline { 2 - 6 } & Cộng đồng & $9,4 \pm 1,6$ & $>0,05$ & $45,0 \pm 7,0$ & $>0,05$ \\
\cline { 2 - 6 } & Khác & $9,0 \pm 1,7$ & $>0,05$ & $47,3 \pm 6,6$ & $<\mathbf{0 , 0 5}$ \\
\hline
\end{tabular}

Nhân xét: Điểm trung bình về kiến thức của

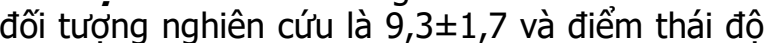
là $44,8 \pm 7,2$. Trong đó có sự khác biệt về điểm kiến thức giữa nam và nữ $(p<0,01)$. Những sinh viên nhận nguồn kiến thức từ Bộ $Y$ tế, người thân/bạn bè có điểm kiến thức trung bình cao hơn so với nhóm không nhận từ những nguồn khác $(p<0,05)$. Những sinh viên nhận nguồn kiến thức từ Bộ Y tế; trường đại học/cao đẳng; người thân/bạn bè và các nguồn khác có điểm thái độ trung bình cao hơn so với nhóm không nhận từ những nguồn khác $(p<0,05)$.

\section{BÀN LUÂN}

Nghiên cứu của chúng tôi bao gôm 597 sinh viên của trường Cao đẳng $Y$ tế Hà Nội. Về chi tiết, kết quả cho thất tỷ lệ trả lời chính xác cao cho các câu hỏi liên quan đến tác nhân gây bệnh $(85,4 \%)$, đường truyền bệnh chính $(99,0 \%)$ và mang phương tiện phòng hộ cá nhân (98,0\%) kết quả này cao hơn so với các nghiên cứu trước đây [7],[8]. Điều này có thể là do sự phổ biến thông tin về COVID-19 trên các phương tiện thông tin đại chúng và các thông điệp cảnh báo hằng ngày từ Chính phủ cũng như các chiến dịch giáo dục tại cộng đông với trọng tâm là thông điệp 5K. Tuy nhiên, chúng tôi cũng nhận thấy mức kiến thức chưa cao, chỉ trên mức trung bình tại nội dung về triệu chứng thường gặp của bệnh (54,9\%) kết quả này tương đồng với nghiên cưuu của Duong $M C$ và cộng sự [8] thấp hơn so với nghiên cứu của Gao Z [7]. Điều này có thể là do đây là một bệnh hoàn toàn mới với sự thay đổi cũng như phát sinh của các triệu chứng diển ra liên tục dẫn đến thiếu sự cập nhật thông tin này ở các em sinh viên. Kết quả của chúng tôi cũng cho thây tỷ lệ sinh viên có hiểu biết về thời gian ủ bệnh trung bình của COVID-19 chiếm tỷ lệ cao $(89,1 \%)$, kết quả này cao hơn so với nghiên cứu của Peng Y và cộng sự [6].

Đa phân đối tượng nghiên cứu đều có thái độ tích cực về việc bệnh có thể ngăn chặn bằng việc áp dụng các biện pháp phòng ngừa $(89,4 \%)$ kết quả này tương đồng với nghiên cứu của AlHanawi MK[9]. Bên cạnh đó các sinh viên cũng có thái độ tích cực vào các nội dung khác bày tỏ sự tin tưởng với đội ngũ nhân viên y tế tuyến đâu chống dịch như sự tham gia phòng chống dịch của của nhân viên y tế làm giảm tỷ lệ mắc COVID-19 (83,9\%); nhân viên y tế nên sẵn sàng tham gia phòng chống dịch tại công đồng (93,3\%). Thái độ tích cực và sự tin tưởng cao vào việc kiểm soát COVID-19 có thể được lý giải do sự hành động chưa từng có của chính phủ với sự tham gia của nhiều các ban ngành như y tế, truyên thông đại chúng, giáo dục, công vụ và quốc phòng trong việc thực hiện các biện pháp kiểm soát nghiêm ngặt và phòng ngừa đối với COVID-19. Tuy nhiên, một số kết quả cũng phản ảnh thái độ tiêu cực về nguy cơ mắc bệnh COVID-19 của bản thân(30,4\%) và gia đình $(28,2 \%)$, các nghiên cứu trước đây cũng cho kết quả phản hồi tương đương với nghiên cứu của chúng tôi [9].

Nghiên cứu cũng cho thấy điểm số về kiến thức trung bình của đối tượng nghiên cứu là $9,3 \pm 1,7$ dao động trong khoảng từ 1 đến 13 , trong đó nữ giới có điểm kiến thức trung bình cao hơn so với nam giới ( $p<0,001)$, kết quả này của chúng tôi tương đồng với nghiên cứu của Zhong BL và cộng sự. Trong nghiên cứu của chúng tôi cho thấy không có sự khác biệt về điểm số kiến thức giữa các năm học, kết quả này không cho thấy sự tương đồng so với các nghiên cứu thực hiện trước đây,[9], chúng tôi tin rằng trình độ học vấn và thời gian tiếp xúc với thực hành lâm sàng sẽ ảnh hưởng đến mức độ hiểu biết cửa sinh viên và cần có những nghiên cứu với cỡ mẫu lớn hơn để làm sáng tỏ điêuu này. Kết quả nghiên cứu cũng cho thấy việc tiếp nhân thông tin về COVID-19 từ các nguồn chính thống như Bộ Y tế, trường đại học/cao đẳng hay từ người thân/bạn bè sẽ cho điểm số về kiến thức cũng như thái độ cao hơn $(p<0,05)$ so với việc tiếp nhận thông tin từ các nguồn khác. Cho thấy, việc tiếp nhận thông tin từ các nguồn tin cậy sẽ giúp cho người thu nhập thông tin có thái độ tốt hơn.

Trong bối cảnh đại dịch tiếp tục tiến triển trên toàn câu và ở Việt Nam được minh chứng bằng sự xuất hiện của các đợt đại dịch mới, nghiên cứu này rất hữu ích cho các nhà hoạch định chính sách y tế và các nhà giáo dục y tế để thiết kế một kế hoạch có hệ thống để đảm bảo rằng sinh viên y khoa có kiến thức, thái độ tốt về đại dịch COVID-19 và các biện pháp phòng ngừa. Tuy nhiên, nghiên cứu của chúng tôi cũng có 
những hạn chế nhất định như nghiên cứu chỉ được thực hiện tại một trường cao đẳng, do đó khổng thể suy rộng cho sinh viên hệ điều dưỡng nói chung. Ngoài ra bô câu hỏi được thu thâp bằng phương pháp tự điền do đó sinh viên có thể trao đổi ảnh hưởng đến việc đo lường kiến thức của từng cá nhân.

\section{KẾT LUẬN}

Nói chung, tỷ lệ sinh viên điều dưỡng có kiến thức tốt về COVID-19 khá cao. Tuy nhiên tỷ lệ trả lời đúng thấp đối với các câu hỏi liên quan đến điều trị, các triệu chứng về COVID-19 và hệ thống dự phòng bệnh tại Việt Nam. Bên cạnh đó đa phần sinh viên đã có thái độ tích cực về COVID-19. Do đó, các mảng kiến thức có tỷ lệ trả lời đúng thấp các các yếu tố giới tính cũng như nguồn cung cấp thông tin về Covid-19 cần được xem xét khi thực hiện các khóa đào tạo về sức khỏe cộng đồng cho sinh viên.

\section{TÀI LIẸU THAM KHẢO}

1. Huang $C$, Wang $Y$, Li $X$ et al (2020). Clinical features of patients infected with 2019 novel coronavirus in Wuhan, China. Lancet (London, England), 395(10223), 497-506.
2. Cutler D (2020). How Will COVID-19 Affect the Health Care Economy? Jama, 323(22), 2237-2238.

3. Bô $\mathbf{Y}$ tế. Trang tin về dich bênh viêm đường hô hẩp cấp COVID-19. https:// ncov.moh.gov.vn/ vi/web/guest/ trang-chu. Published 2019. Accessed 24-06-2021.

4. Ha BTT, Ngoc Quang L (2020). Combating the COVID-19 Epidemic: Experiences from Vietnam. 17(9).

5. Ikhlaq A, Hunniya B-E, Riaz IB et al (2020). Awareness and attitude of undergraduate medical students towards 2019-novel corona virus. Pakistan Journal of Medical Sciences, 36(COVID19-S4), S32.

6. Peng $Y$, Pei $C$, Zheng $Y$ et al (2020). Knowledge, attitude and practice associated with COVID-19 among university students: a crosssectional survey in China.

7. Gao Z, Ying S, Liu J et al (2020). A crosssectional study: Comparing the attitude and knowledge of medical and non-medical students toward 2019 novel coronavirus. Journal of infection and public health, 13(10), 1419-1423.

8. Duong MC, Nguyen HT, Duong BT et al The Levels of COVID-19 Related Health Literacy among University Students in Vietnam, Infect Chemother. 2021 Mar;53(1):107-17. doi: 10.3947/ic.2020.0152. Epub 2021 Mar 16.

9. Al-Hanawi MK, Angawi $K$, Alshareef $\mathbf{N}$ et al (2020). Knowledge, Attitude and Practice Toward COVID-19 Among the Public in the Kingdom of Saudi Arabia: A Cross-Sectional Study. Frontiers in public health, 8, 217.

\section{ĐÁNH GIÁ KẾT QUẢ PHẪU THUÂT NộI SOI MŨI XOANG TYPE III, IV CÓ SỬ DỤNG AQUAMANTYS}

\section{TÓM TẮT}

Aquamantys là môtt thế hệ dao plasma hàn mach cầm máu mới được ứng dụng trong các phẫu thuật đòi độ chính xác cao và có nhiêu ưu điểm trong câm máu. Mục tiêu nghiên cứu: Đánh giá kết quả sau phẫu thuật nội soi mũi xoang (type III, IV) có sử dụng dao plasma Aquamatys. Phương pháp nghiên cứu: can thiệp có đối chứng gồm 21 bệnh nhân nhóm nghiên cứu (có sử dụng Aquamatys) và 20 bệnh nhân nhóm chứng (không được sử dụng Aquamatys) có chỉ định phẫu thuật nội soi mũi xoang (type III và IV) tại Bệnh viện Đại học Y Hà Nội trong thời gian từ 8/2020 đến 8/2021. Kết quả nghiên cựu: Hệ thống Aquamantys giúp giảm thời gian phẫu thuật, giảm lương máu mất trong phẫu thuât thông qua thời gian phẫu thuật của nhóm nghiên cứu là 78,9 $\pm 22,4$ phút

\footnotetext{
${ }^{1}$ Bệnh viện Đa Khoa tỉnh Quảng Ninh

${ }^{2}$ Trường Đại học Y Hà Nội

Chiu trách nhiệm chính: Vũ Thành Khoa

Email: khoatmhhlqn@gmail.com

Ngày nhận bài: 8.7.2021

Ngày phản biên khoa họ: 3.9.2021

Ngày duyệt bài: 10.9.2021
}

\section{Vũ Thành Khoa ${ }^{1}$, Cao Minh Thành ${ }^{2}$} ngắn hơn có ý nghĩa thống kê so với nhóm chứng là $94,0 \pm 21,5$ phút với $p<0,05$. Và lượng máu mất ở nhóm nghiên cứu là $86,7 \pm 42,3 \mathrm{ml}$ thấp hơn có ý nghĩa thống kê so với nhóm chứng là $116,0 \pm 41,8 \mathrm{ml}$ với $p<0,05$. Triệu chứng cơ năng theo thang VAS cho thây sau phẫu thuật 5 ngày ở nhóm nghiên cứu có xu hướng nhẹ hơn so với nhóm chứng $(p>0,05)$ và sau phẫu thuật 2 tuần và 2 tháng ở nhóm nghiên cứu tương đưởng với nhóm chứng $(p>0,05)$. Triệu chứng thức thể sau phẫu thuât 2 tháng giữa 2 nhóm không thấy khác biệt với $p>0,05$. Bệnh nhân có dính hay xơ seo trong hốc mũi thấp, không khác nhau giữa nhóm nghiên cứu và nhóm chứng. Kết luận: hệ thống Aquạamantys là an toàn và có hiệu quả cẩm máu trong phâuu thuật nội soi mũi xoang.

Tư khóa: nội soi mũi xoang, viêm mũi xoang mạn tính, Plasma Aquamantys, cầm máu

\section{SUMMARY \\ EVALUATION THE RESULT OF ENDOSCOPIC ENDONASAL SURGERY (TYPE III, IV) BY USING AQUAMATYS}

Aquamantys is new generation of coagulate plasma blade applied on precision bleeding control and advantage on coagulate soft tissue. Purpose: 